\title{
Primary Total Elbow Replacement for Treatment of Complex Distal Humerus Fracture: Outcomes of Short-term Follow-up
}

\author{
Du-Han Kim, Beom-Soo Kim, Chung-Sin Baek, Chul-Hyun Cho \\ Department of Orthopedic Surgery, Dongsan Medical Center, Keimyung University School of Medicine, Daegu, Korea
}

\begin{abstract}
Background: High complication rate after open reduction and internal fixation can lead to use of primary total elbow replacement (TER) in treatment of complex distal humerus fractures in elderly patients. The purpose of this study was to investigate the short-term outcomes and complications after primary TER in patients with complex distal humerus fracture.

Methods: Nine patients with acute complex distal humerus fracture were treated by primary TER using the semiconstrained Coonrad-Morrey prosthesis. The mean age of patients was 72.7 years (range, 63-85 years). Clinical and radiographic outcomes were evaluated over a mean follow-up of 29.0 months (range, 12-65 months) using visual analog scale (VAS) score for pain; Mayo elbow performance score (MEPS); Quick Disabilities of the Arm, Shoulder, and Hand (Quick-DASH) score; and serial plain radiographs. Complications were also evaluated. Results: At the final follow-up, mean VAS, MEPS, and Quick-DASH scores were 1.2, 80.5, and 20, respectively. The mean range of motion was $127.7^{\circ}$ of flexion, $13.8^{\circ}$ of extension, $73.3^{\circ}$ of pronation, and $74.4^{\circ}$ of supination. There was no evidence of bushing wear or high-grade implant loosening on serial plain radiographs. Three complications (33.3\%) comprising two periprosthetic fractures and one ulnar neuropathy were observed.

Conclusions: Primary TER for treatment of complex distal humerus fractures in elderly patients yielded satisfactory short-term outcomes. However, surgeons should consider the high complication rate after primary TER.
\end{abstract}

Keywords: Elbow; Arthroplasty; Fracture; Complications; Total joint replacement; Clinical outcome

\section{INTRODUCTION}

Distal humerus fractures in the elderly are increasing with the aging population and are difficult to treat and challenging for orthopedic surgeons. The gold standard for treatment of displaced distal humerus fractures is open reduction and internal fixation (ORIF), along with early mobilization [1]. However, these fractures are often complicated by comminution, bone loss, intra-articular involvement, and poor bone quality. Complex distal hu- merus fractures in elderly patients may have inadequate internal fixation such that bony union is difficult. Successful treatment requires long-term immobilization and produces unsatisfactory clinical outcomes with complications [2]. The complication rate after ORIF for distal humerus fractures has been reported as over $35 \%[1,2]$. The complications include fixation failure, nonunion, heterotopic ossification, ulnar neuropathy, and stiffness $[1,2]$. These difficulties have led to use of total elbow replacement (TER) as a primary treatment option for complex distal humerus frac-

Received: January 29, 2020 Accepted: February 10, 2020

Correspondence to: Chul-Hyun Cho

Department of Orthopedic Surgery, Dongsan Medical Center, Keimyung University School of Medicine, 56 Dalseong-ro, Jung-gu, Daegu 41931, Korea Tel: +82-53-258-4772, Fax: +82-53-258-4773, E-mail: oscho5362@dsmc.or.kr, ORCID: https://orcid.org/0000-0003-0252-8741

Financial support: None.

Conflict of interest: None.

Copyright(C) 2020 Korean Shoulder and Elbow Society. All Rights Reserved.

This is an Open Access article distributed under the terms of the Creative Commons Attribution Non-Commercial License (http://creativecommons.org/licenses/by-nc/4.0/) which permits unrestricted non-commercial use, distribution, and reproduction in any medium, provided the original work is properly cited. 
tures in elderly patients.

Several studies have reported that primary TER produces superior outcomes compared with ORIF and is a reasonable option for elderly patients with comminuted intra-articular distal humerus fractures [3-6]. Over the last decade, the number of displaced distal humerus fractures in elderly patients treated with TER has increased dramatically because of the aging population [7]. The advantages of TER over ORIF include early rehabilitation and satisfactory short-term outcomes. However, the disadvantages include surgeon-imposed activity restrictions and several catastrophic complications including infection, aseptic loosening, periprosthetic fracture, and potential need for revision arthroplasty [8]. With these distinct benefits and risks, it remains unclear whether TER should be a primary treatment of distal humerus fractures in elderly patients. The purpose of this study was to investigate the outcomes and complications after primary TER in patients with complex distal humerus fracture.

\section{METHODS}

This study was approved from the Institutional Review Board of Dongsan Medical Center with exemption of informed consent (IRB No. 2019-10-030).

Between 2012 and 2019, we treated 16 patients with primary TER for acute complex distal humerus fractures. Nine of 16 patients were retrospectively reviewed because six had died and one was unreachable. Inclusion criteria were (1) age older than 60 years at the time of initial trauma, (2) primary TER for acute fractures, and (3) follow-up period longer than 12 months after surgery. The decision to perform TER was based on patient age and working status, degree of comminution with intra-articular involvement, osteoporosis, and medical comorbidity.

The mean age of the patients was 72.7 years (range, 63-85 years). There were five women and four men. The mechanism of injury was slip in seven patients and fall in two patients. According to AO classification, seven patients had type C3 fracture, one had type A2 fracture, and one had type A3 fracture. One patient had an open fracture. The mean interval from initial trauma to TER was 27.8 days (range, 5-85 days) (Table 1). Three patients underwent temporary external fixation because of one open fracture, one impending compartment syndrome, and one ipsilateral proximal humerus fracture with poor condition of the soft tissue around the elbow joint. One patient with impending compartment syndrome underwent fasciotomy only.

All patients were treated using the semiconstrained Coonrad-Morrey prosthesis (Zimmer, Warsaw, IN, USA) via a triceps reflecting approach, and the ulnar nerve was transposed anteriorly. After surgery, a long-arm splint was applied in full extension to prevent wound perturbation. Passive and active motion exercises were started 2 weeks after surgery.

The mean follow-up period of patients was 29.0 months (range, 12-65 months). Clinical outcomes were assessed using the visual analog scale (VAS) score for pain; Mayo elbow performance score (MEPS); the Quick Disabilities of the Arm, Shoulder, and Hand (Quick-DASH) score; and active range of motion (ROM) of the elbow joint. Serial plain radiographs were performed for all patients to evaluate fixation status, bushing wear, and implant loosening. The cementing technique was evaluated on immediate postopera-

Table 1. The demographic data of patients

\begin{tabular}{|c|c|c|c|c|c|c|c|c|c|}
\hline Case & Age (yr) & Sex & Side & $\begin{array}{c}\text { Injury } \\
\text { mechanism }\end{array}$ & $\begin{array}{c}\mathrm{AO} \\
\text { classification }\end{array}$ & Associated injury & $\begin{array}{c}\text { Time to } \\
\text { surgery (day) }\end{array}$ & Medical comorbidity & $\begin{array}{l}\text { Follow-up } \\
\text { (mo) }\end{array}$ \\
\hline 1 & 73 & $\mathrm{~F}$ & Rt & Slip down & $\mathrm{C} 3$ & & 5 & Hypertension & 48 \\
\hline 2 & 67 & $\mathrm{M}$ & Rt & Slip down & $\mathrm{C} 3$ & Open fracture & 30 & $\begin{array}{l}\text { Hypertension, liver } \\
\text { cirrhosis }\end{array}$ & 44 \\
\hline 3 & 71 & $\mathrm{~F}$ & $\mathrm{Lt}$ & Slip down & $\mathrm{C} 3$ & & 18 & Hypertension & 23 \\
\hline 4 & 70 & $\mathrm{M}$ & Rt & Fall down & $\mathrm{C} 3$ & $\begin{array}{l}\text { Impending compart- } \\
\text { ment syndrome }\end{array}$ & 61 & $\begin{array}{l}\text { Gastric cancer, hy- } \\
\text { pertension }\end{array}$ & 21 \\
\hline 5 & 71 & $\mathrm{M}$ & $\mathrm{Lt}$ & Slip down & $\mathrm{C} 3$ & $\begin{array}{l}\text { Impending compart- } \\
\text { ment syndrome }\end{array}$ & 85 & & 20 \\
\hline 6 & 85 & $\mathrm{~F}$ & $\mathrm{Lt}$ & Slip down & A3 & & 5 & $\begin{array}{l}\text { Cerebral infarction, } \\
\text { hypertension }\end{array}$ & 12 \\
\hline 7 & 63 & $\mathrm{~F}$ & Rt & Slip down & $\mathrm{C} 3$ & & 7 & $\begin{array}{l}\text { Hypertension, hy- } \\
\text { percholesterolemia }\end{array}$ & 65 \\
\hline 8 & 84 & $\mathrm{~F}$ & $\mathrm{Lt}$ & Slip down & $\mathrm{A} 2$ & & 8 & Dementia & 15 \\
\hline 9 & 71 & $\mathrm{M}$ & Rt & Fall down & $\mathrm{C} 3$ & $\begin{array}{l}\text { Ipsilateral proximal } \\
\text { humerus fracture }\end{array}$ & 32 & $\begin{array}{l}\text { Diabetes mellitus, } \\
\text { hypertension }\end{array}$ & 13 \\
\hline
\end{tabular}

F, female; M, male; Rt, right; Lt, left. 
tive radiographs for both components and was classified into three types (adequate, marginal, inadequate) as described by Morrey [9]. Bushing wear was assessed via anteroposterior radiograph at the final follow-up evaluation and was classified into three grades (normal, mild to moderate, extensive) as described by Ramsey et al. [10] Implant loosening was graded on anteroposterior and lateral radiographs according to the classification described by Morrey et al. [9] Radiolucency was graded as type 0 if the radiolucent line was less than $1 \mathrm{~mm}$ wide and involved less than $50 \%$ of the interface, type 1 if the radiolucent line was at least $1 \mathrm{~mm}$ wide and involved less than $50 \%$ of the interface, type 2 if the radiolucent line was more than $1 \mathrm{~mm}$ wide and involved more than $50 \%$ of the interface, type 3 if the radiolucent line was more than $2 \mathrm{~mm}$ wide and surrounded the entire interface, and type 4 if there was gross loosening [9].

\section{RESULTS}

At the final follow-up evaluation, the mean VAS score for pain was 1.2. Four patients had no pain, four had mild pain, and one had moderate pain. The mean MEPS was 80.5 , with two excellent, five good, and two fair results. The mean Q-DASH score was 20. The mean ROM was $127.7^{\circ}$ of flexion, $13.8^{\circ}$ of extension, $73.3^{\circ}$ of pronation, and $74.4^{\circ}$ of supination (Table 2 ).

For the cement technique on immediate postoperative radiographs, five cases showed adequate adherence, and four cases had marginal adherence. Bushing wear was not observed on the final radiographs in all cases. According to loosening grade, there were three type 0 , four type 1 , and two type 2 cases on the final radiographs. Three complications $(33.3 \%)$ were observed in nine patients; two patients with periprosthetic fracture around the humeral component with minor trauma were treated with ORIF and showed fair clinical results at the final follow-up. One patient had progressive ulnar neuropathy after TER and underwent adhesiolysis and decompression of the ulnar nerve at 5 months after TER.

\section{Case 1}

A 73-year-old woman (no. 1) was hospitalized for intercondylar comminuted fracture of the right distal humerus after a slip. On the 5th day after injury, we performed primary TER. At 48 months follow-up after TER, the patient had satisfactory clinical outcomes with no evidence of implant loosening (Fig. 1).

\section{Case 2}

A 63-year-old woman (no. 7) was hospitalized for intra-articular comminuted fracture of the right distal humerus after a slip. On the 7th day after injury, we performed primary TER. After surgery, the patient complained of a tingling sensation of the fourth and fifth fingers. At 5 months after surgery, we performed adhesiolysis and decompression of the ulnar nerve for progressive ulnar neuropathy with clawing deformity. At the 65-month follow-up after TER, the patient had excellent clinical outcomes with no evidence of implant loosening. Ulnar neuropathy was resolved completely (Fig. 2).

\section{DISCUSSION}

Although the number of distal humerus fractures in elderly patients has increased in the last decades, the results after ORIF in elderly patients with complex distal humerus fractures are highly variable, with many failures and poor outcomes [3-6]. Originally, TER was restricted to manage rheumatoid arthritis, posttraumatic arthritis, and fracture nonunion of the distal humerus. Recent studies have reported that primary TER for complex distal humerus fractures in elderly patients may be an alternative treatment with satisfactory outcomes [11-14]. TER involves immediate sta-

Table 2. Summary of the outcomes and complication after total elbow replacement in patients with complex distal humerus fracture

\begin{tabular}{|c|c|c|c|c|c|c|c|c|c|c|c|}
\hline \multirow{2}{*}{ Case } & \multirow{2}{*}{$\begin{array}{l}\text { Cementing } \\
\text { technique }\end{array}$} & \multirow{2}{*}{$\begin{array}{c}\text { Bushing } \\
\text { wear }\end{array}$} & \multirow{2}{*}{$\begin{array}{l}\text { Loosening } \\
\text { grade }\end{array}$} & \multirow{2}{*}{$\begin{array}{l}\text { VAS } \\
\text { score }\end{array}$} & \multirow{2}{*}{ MEPS } & \multirow{2}{*}{$\begin{array}{l}\text { Q-DASH } \\
\text { score }\end{array}$} & \multicolumn{4}{|c|}{ ROM } & \multirow{2}{*}{ Complication } \\
\hline & & & & & & & Flexion & Extension & Pronation & Supination & \\
\hline 1 & Adequate & Normal & 0 & 0 & 100 & 12 & 120 & 10 & 80 & 80 & \\
\hline 2 & Adequate & Normal & 2 & 3 & 80 & 23 & 140 & 0 & 80 & 80 & \\
\hline 3 & Adequate & Normal & 2 & 4 & 65 & 19 & 150 & 0 & 80 & 80 & Periprosthetic fracture \\
\hline 4 & Marginal & Normal & 0 & 0 & 80 & 12 & 120 & 15 & 70 & 70 & \\
\hline 5 & Marginal & Normal & 1 & 1 & 80 & 15 & 105 & 5 & 70 & 70 & \\
\hline 6 & Marginal & Normal & 1 & 1 & 80 & 35 & 145 & 45 & 60 & 70 & \\
\hline 7 & Adequate & Normal & 0 & 0 & 100 & 12 & 150 & 0 & 80 & 80 & Ulnar neuropathy \\
\hline 8 & Adequate & Normal & 1 & 0 & 80 & 25 & 120 & 30 & 70 & 70 & \\
\hline 9 & Marginal & Normal & 1 & 2 & 60 & 27 & 100 & 20 & 70 & 70 & Periprosthetic fracture \\
\hline
\end{tabular}

VAS, visual analog scale; MEPS, Mayo elbow performance score; Q-DASH, Quick Disabilities Of Arm, Shoulder, and Hand; ROM, range of motion. 

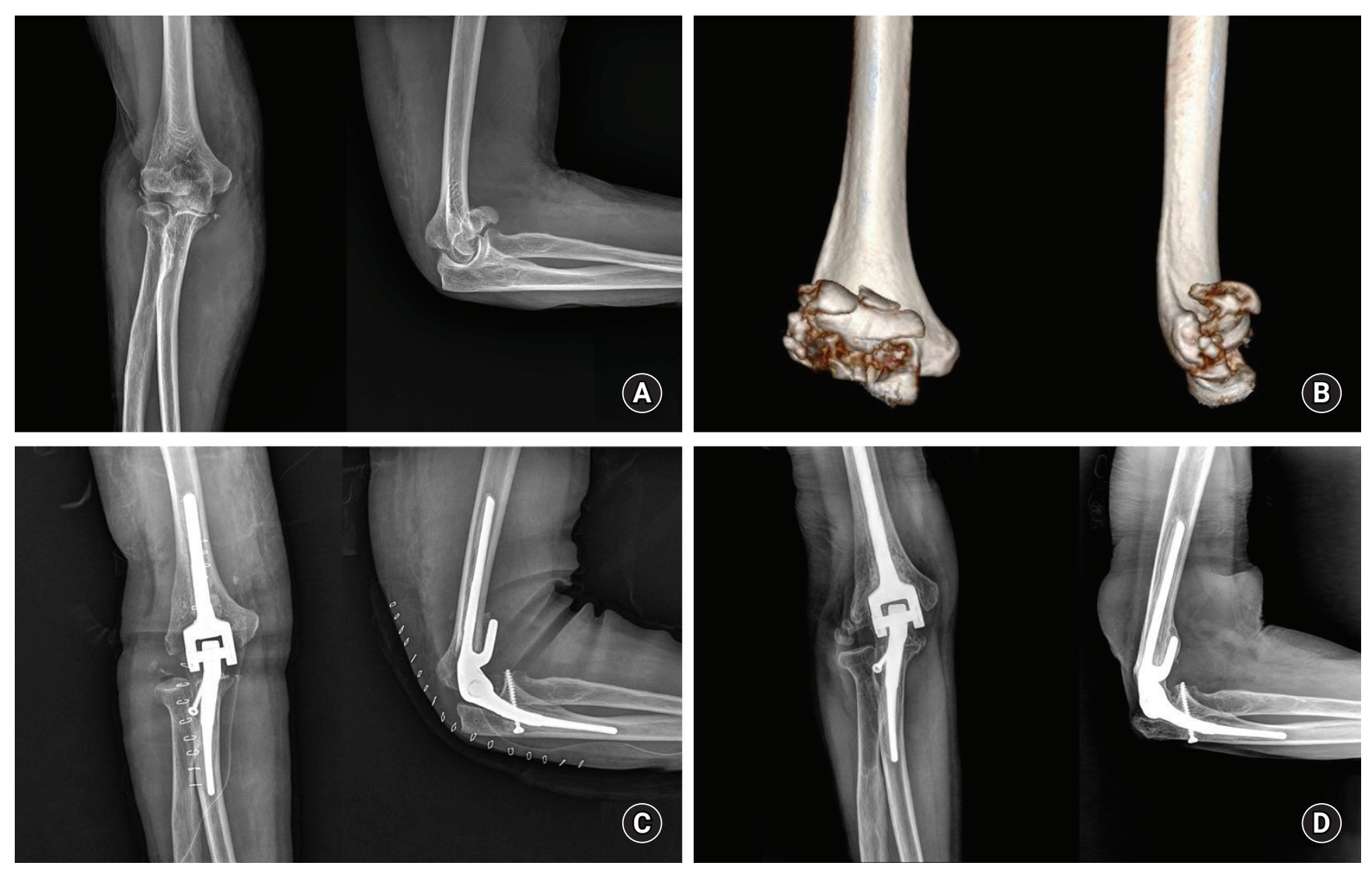

Fig. 1. (A, B) Initial radiographs and three-dimensional computed tomography images of a 73-year-old woman show an intercondylar comminuted fracture of the right distal humerus. (C) Immediate radiographs after total elbow replacement. (D) Radiographs at 48 months after surgery show no evidence of loosening with excellent clinical outcome.

bility, early mobilization, faster rehabilitation, and better shortterm functional result in older low-demand patients with osteoporosis [4]. However, TER may accompany considerable postoperative complications such as infection, implant loosening, neurological problems, and periprosthetic fracture.

Several studies have reported short- to long-term outcomes and complication rate after TER for complex distal humerus fractures [5,6,11,12,14]. In 1997, Cobb and Morrey [12] first reported a series of 21 elderly patients who underwent primary TER for comminuted distal humerus fractures. They reported good or excellent results in $95 \%$ of patients at a mean follow-up of 3.3 years, with a reoperation rate of 5\%. Lami et al. [14] reported 21 patients receiving TER for distal humerus fractures with a mean follow-up of 3.2 years, mean MEPS of 84, Q-DASH score of 32.4, mean flexion of $125^{\circ}$, and mean loss of extension of $22^{\circ}$. The complication rate was 9.5\% without any revision surgery. Lee et al. [5] reported seven elderly Asian patients with distal humerus fractures treated with TER and achieved six excellent results and one good result in patients with low physical demands. The mean MEPS was 94.3 points, and mean follow-up was 24.9 months. Barco et al. [11] re- ported 44 TER in treatment of distal humerus fracture; patients were followed for a minimum of 10 years. The mean VAS for pain was 0.6 , the mean flexion was $123^{\circ}$, and mean loss of extension was $24^{\circ}$. The mean MEPS was 90.5 points, with three patients scoring $<75$ points.

Mckee et al. [2] conducted a prospective, randomized, controlled trial to compare functional outcomes, complications, and reoperation rates in elderly patients with displaced intra-articular distal humeral fractures treated with ORIF or primary semi-constrained TER. They reported that TER resulted in more predictable and improved 2-year functional outcomes compared with ORIF and may result in decreased reoperation rates (12\% in TER group vs. $29 \%$ in ORIF group) [2]. Five patients randomized to ORIF were converted to TER intraoperatively because of extensive comminution and inability to obtain sufficient stability to allow early ROM [2]. Frankle et al. [3] conducted a retrospective comparison of ORIF with TER for intra-articular distal humerus fractures in 24 women aged older than 65 years. At a minimum of 2 years, TER resulted in excellent or good results in all 12 patients, with improved ROM and less physical therapy required compared with an 

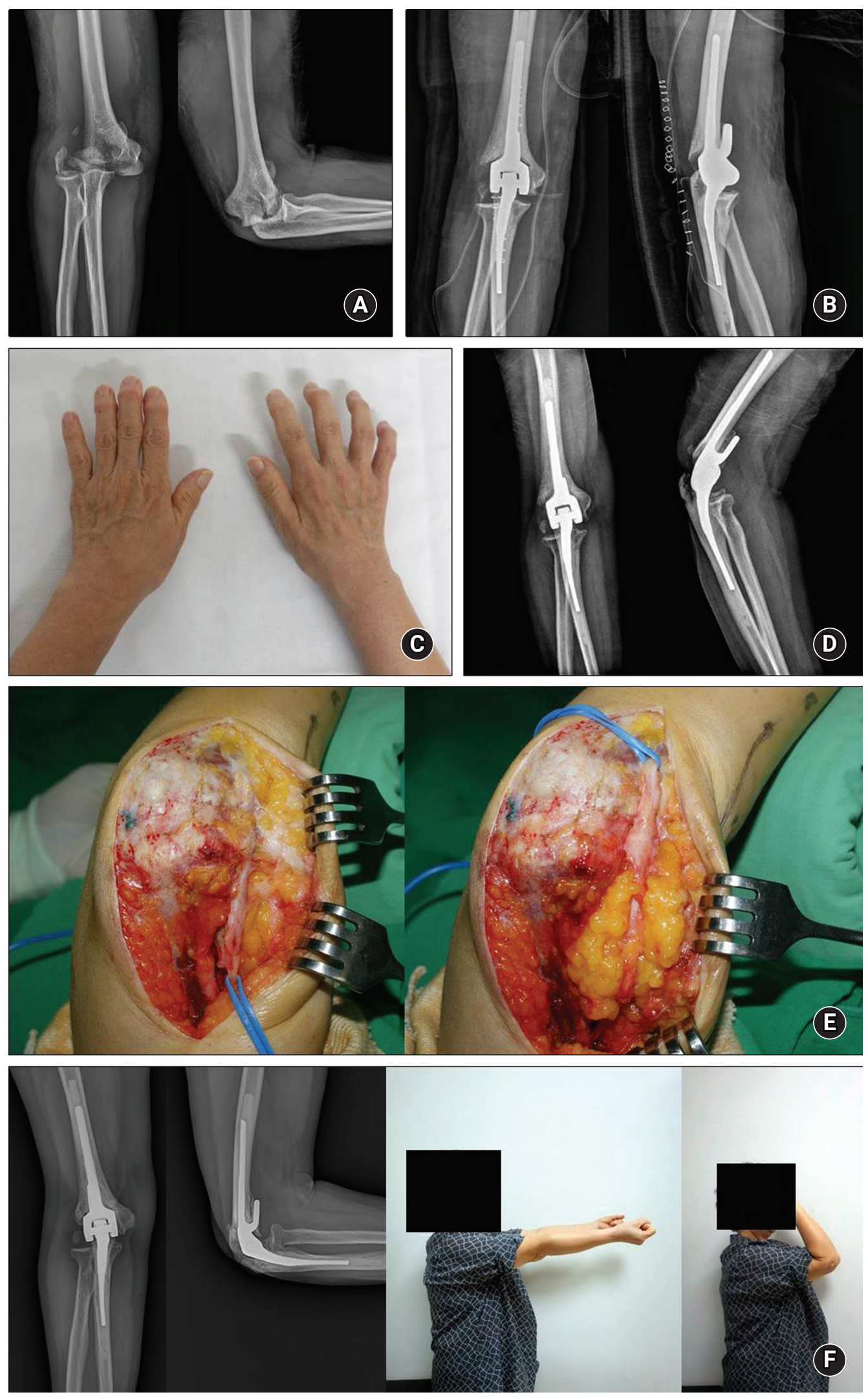

Fig. 2. (A) Initial radiographs of a 63-year-old woman show a comminuted intra-articular fracture on the right distal humerus. (B) Immediate radiographs after total elbow replacement. (C) Right fourth and fifth finger clawing deformity at 5 months after surgery. (D) Radiographs at 5 months after surgery. (E) Intraoperative findings of adhesion of the ulnar nerve. (F) Radiographs at 65 months after surgery show no evidence of loosening. Clinial photos show full elbow flexion and extension. 
ORIF group. Federer et al. [13] investigated total cost and effectiveness of TER compared to ORIF and reported that TER was slightly more cost effective than ORIF in elderly patients with acute intra-articular distal humerus fractures. In a systematic review by Githens et al. [8], 27 studies with 563 patients showed a mean follow-up after TER of 45.9 months, whereas follow-up after ORIF was 43 months. That group reported no clinically evident difference in functional outcomes as measured by ROM and functional scores [8]. Although total complications were more frequent after TER, major complications were more frequent after ORIF [8]. However, the study quality in that systematic review was generally weak. Because the optimal treatment for complex distal humerus fractures has not yet established, further prospective randomized trials are needed to assess and determine the most appropriate surgical intervention for complex distal humerus fracture.

A systematic review article by Chalidis et al. [4] reported nine clinical studies describing the results and complications of TER in 167 patients with 169 distal humerus fractures. Complications included wound infection (5.4\%), ulnar nerve lesion (6.5\%), reflex sympathetic dystrophy (3\%), and periprosthetic fracture (1.7\%). Barco et al. [11] reported a 92\% survival rate for elbows without rheumatoid arthritis at both 5 and 10 years, but complication was frequent; 23 events (52\%) were observed in 44 patients. Prasad and Dent [6] reported their experience of 19 TER for distal humerus fracture with a minimum 10-year follow-up. Only 53\% of nonrheumatoid patients who undergo TER for distal humerus fractures survive to the 10th anniversary of their index procedure. They concluded that surgeons undertaking these procedures should be aware of the long-term revision rates and the sex difference in rates of loosening [6].

In the present study, mean VAS score, MEPS, and Quick-DASH at the mean follow-up of 29 months were 1.2, 80.5, and 20, respectively. The mean ROM was $127.7^{\circ}$ of flexion, $13.8^{\circ}$ of extension, $73.3^{\circ}$ of pronation, and $74.4^{\circ}$ of supination. Moreover, there was no evidence of bushing wear or high-grade implant loosening on serial plain radiographs. Our study demonstrated that primary TER produces satisfactory short-term functional and radiographic outcomes in patients with complex distal humerus fractures. However, we detected three complications $(33.3 \%)$ in nine cases, including two periprosthetic fractures and one ulnar neuropathy that required secondary operation. The patient with progressive ulnar neuropathy recovered completely after adhesiolysis and decompression of the ulnar nerve at 5 months after TER, but two patients with periprosthetic fracture were treated with ORIF and showed unsatisfactory clinical outcomes at the final follow-up. In terms of TER indication, primary TER for complex distal humerus fractures should be selected carefully based on patient age, bone quality, comorbidities, soft tissue condition, and intra-articular comminution because of potentially considerable postoperative complications.

This study has several limitations. First, it was a retrospective study with a small number of cases. Second, the results may not be generalizable because seven (43.7\%) of 16 patients died or were lost during follow-up. Third, the follow-up period was relatively short and did not allow exact radiographic results including bushing wear or implant loosening in long-term implant survival. In the future, long-term prospective studies are needed to evaluate clinical and radiographic outcomes after TER for complex distal humerus fractures.

This study revealed that primary TER for treatment of complex distal humerus fractures in elderly patients yielded satisfactory short-term outcomes. However, surgeons should consider the high complication rate after primary TER.

\section{ORCID}

Du-Han Kim

https://orcid.org/0000-0002-6636-9340

Beom-Soo Kim

https://orcid.org/0000-0002-8728-512X

Chung-Sin Baek

https://orcid.org/0000-0002-4184-2568

Chul-Hyun Cho

https://orcid.org/0000-0003-0252-8741

\section{REFERENCES}

1. Korner J, Lill H, Muller LP, et al. Distal humerus fractures in elderly patients: results after open reduction and internal fixation. Osteoporos Int 2005;16 Suppl 2:S73-9.

2. McKee MD, Veillette CJ, Hall JA, et al. A multicenter, prospective, randomized, controlled trial of open reduction--internal fixation versus total elbow arthroplasty for displaced intra-articular distal humeral fractures in elderly patients. J Shoulder Elbow Surg 2009;18:3-12.

3. Frankle MA, Herscovici D Jr, DiPasquale TG, Vasey MB, Sanders RW. A comparison of open reduction and internal fixation and primary total elbow arthroplasty in the treatment of intraarticular distal humerus fractures in women older than age 65. J Orthop Trauma 2003;17:473-80.

4. Chalidis B, Dimitriou C, Papadopoulos P, Petsatodis G, Giannoudis PV. Total elbow arthroplasty for the treatment of insufficient distal humeral fractures: a retrospective clinical study and review of the literature. Injury 2009;40:582-90.

5. Lee KT, Lai CH, Singh S. Results of total elbow arthroplasty in the treatment of distal humerus fractures in elderly Asian patients. J Trauma 2006;61:889-92.

6. Prasad N, Dent C. Outcome of total elbow replacement for distal 
humeral fractures in the elderly: a comparison of primary surgery and surgery after failed internal fixation or conservative treatment. J Bone Joint Surg Br 2008;90:343-8.

7. Gay DM, Lyman S, Do H, Hotchkiss RN, Marx RG, Daluiski A. Indications and reoperation rates for total elbow arthroplasty: an analysis of trends in New York State. J Bone Joint Surg Am 2012;94:110-7.

8. Githens M, Yao J, Sox AH, Bishop J. Open reduction and internal fixation versus total elbow arthroplasty for the treatment of geriatric distal humerus fractures: a systematic review and meta-analysis. J Orthop Trauma 2014;28:481-8.

9. Morrey BF, Bryan RS, Dobyns JH, Linscheid RL. Total elbow arthroplasty: a five-year experience at the Mayo Clinic. J Bone Joint Surg Am 1981;63:1050-63.

10. Ramsey ML, Adams RA, Morrey BF. Instability of the elbow treated with semiconstrained total elbow arthroplasty. J Bone
Joint Surg Am 1999;81:38-47.

11. Barco R, Streubel PN, Morrey BF, Sanchez-Sotelo J. Total elbow arthroplasty for distal humeral fractures: a ten-year-minimum follow-up study. J Bone Joint Surg Am 2017;99:1524-31.

12. Cobb TK, Morrey BF. Total elbow arthroplasty as primary treatment for distal humeral fractures in elderly patients. J Bone Joint Surg Am 1997;79:826-32.

13. Federer AE, Mather RC 3rd, Ramsey ML, Garrigues GE. Cost-effectiveness analysis of total elbow arthroplasty versus open reduction-internal fixation for distal humeral fractures. J Shoulder Elbow Surg 2019;28:102-11.

14. Lami D, Chivot M, Caubere A, Galland A, Argenson JN. Firstline management of distal humerus fracture by total elbow arthroplasty in geriatric traumatology: results in a 21-patient series at a minimum 2years' follow-up. Orthop Traumatol Surg Res 2017;103:891-7. 